\title{
PUSAT MEDITASI
}

\author{
Anisa Sisca Rahmariyanti ${ }^{1)}$, Maria Veronica Gandha ${ }^{2)}$ \\ 1) Program Studi S1 Arsitektur, Fakultas Teknik, Universitas Tarumanagara, anissasisca@gmail.com \\ 2) Program Studi S1 Arsitektur, Fakultas Teknik, Universitas Tarumanagara, mariag@ft.untar.ac.id
}

\begin{abstract}
Abstrak
Kota Jakarta sebagai Kota Metropolis terbesar di Asia Tenggara menimbulkan banyak permasalahan didalamnya. Antara lain tingginya jumlah penduduk, kegiatan yang padat, pergerakan yang cepat. Dengan adanya pola hidup penduduk kota seperti itu menjadikan masyarakat kota rentan stres. Jakarta sebagai ibu kota $14 \%$ penduduknya juga mengalami stres. Banyak cara untuk menghilangkan stres, salah satunya dengan wisata. Diperlukan adanya wisata arsitektur yang dapat menjadi atraksi wisata dengan bentuk yang dapat merespon lingkungan sekitar. Wisata arsitektur dapat diartikan sebagai objek yang menjadi atraksi dan pusat pandangan para pengunjung. Meditasi merupakan salah satu teknik untuk merileksasi tubuh, mengosongkan pikiran, dan membangkitkan semangat kembali. Pusat meditasi dapat menjadi destinasi dan atraksi baru ditengah kepadatan dan dinamika ruang metropolis. Sebagai ruang pelarian dari kepadatan kegiatan sehingga pengunjung dapat menjadikan tempat ini sebagai sarana transit, sarana beristirahat sejenak lalu kembali lagi beraktivitas.
\end{abstract}

Kata kunci: Meditasi, Metropolis, Stres, Wisata Arsitektur

\begin{abstract}
Jakarta as the biggets Metropolis City in Southeast Asia has caused many problems and anomalies. High density, tight schedule, and fast movement for instance. These trend of lifestyle could bring stress to society easily. As a capital city, it is estimated that $14 \%$ of population is suffering from stress. There are many ways to overcome stress, just as excursion. Architectural tourism could be the solution to respond the problems arround. This tourism could be interpreted as an object attraction and the center of view of visitors. Meditation is one of the techniques to relax the body, empty minds and bring back the spirit. Meditation Hub could be the new destination surrounded by the hustle and bustle of the metropolis dynamic room. A runaway from the rush so that visitors could use this place as an transit hub, a place for relaxing for some moment before continue the activities
\end{abstract}

Keywords : Architecture Tourism, Meditation, Metropolis, Stress.

\section{PENDAhULUAN}

Kota Jakarta dengan luas $661.52 \mathrm{~km} 2$ dengan jumlah penduduk 10.187.595 jiwa (2011) menjadikannya kota metropolis terbesar di Asia-Tenggara. Salah satu masalah yang dihadapi oleh kota metropolis adalah kepadatan penduduk yang tinggi. United Nations memperkirakan pada tahun 2050, 80\% penduduk dunia akan hidup di kota. Dengan kegiatan aktivitas yang padat dan pergerakan yang cepat, tercipta pemikiran masyarakat bahwa waktu merupakan hal yang sangat berharga. Karena pemikiran itu maka masyarakat kota berlomba-lomba untuk berkerja keras demi bertahan hidup di kota. Dengan pola pemikiran dan hidup seperti itu akan mempengaruhi tenaga dan pikiran seseorang. Aktivitas dan rutinitas kesibukan yang tinggi bisa menjadikan masyarakat kota rentan stress.

Untuk mengatasi stress yang dialami oleh penduduk kota, salah satu cara yang dilakukannya antara lain keluar sesaat dari kegiatan rutin yang selalu dilakukan. Jakarta yang merupakan kota metropolis, masyarakat setiap harinya selalu di sibukkan dengan pekerjaan, masalah kemacetan, dan masalah lainnya. Terdapat hal yang perlu diperhatikan seperti aspek 
kejiwaan dan kesehatan seseorang. Untuk membentuk kota yang ideal maka perlunya peran dari masyarakat didalamnya. Karena masyarakat itu sendiri yang menjadi pembentuk identitas suatu kota.

Berdasarkan sumber dari AtlassandBoots negara dengan tingkatan stress, Indonesia menempati peringkat ke-25 dari 74 di dunia. Sedangkan, laporan dari World Heatlh Organization indonesia menempati urutan ke-4 untuk gangguan depresi dan urutan ke-5 untuk gangguan kecemasan. Dengan kasus sebesar 50\% terjadi pada usia 20-50 tahun. Depresi merupakan penyakit peringkat ke-4 di dunia. WHO meramalkan bahwa pada tahun 2020 depresi akan menjadi penyakit urutan ke-2 di dunia. Sedangkan untuk tahun 2030, peringkat depresi sebagai penyakit dunia akan menempati peringkat ke-1.

Di Jakarta, depresi merupakan penyakit tertinggi ke-3 setelah jantung dan diabetes. Berdasarkan hasil penelitian pasien di Puskesmas se-Jakarta pada tahun 2007, menunjukkan 1 dari 4 warga mengidap stres atau sekitar 1,4 juta jiwa warga Jakarta. Tingkat pengidap stres di Jakarta sudah mencapai angka $14 \%$ dari jumlah populasi, dimana presentase tersebut lebih tinggi dibandingkan dengan angka pengidap stres di Indonesia yang hanya sebesar $11.6 \%$.

Jakarta merupakan kota dengan jumlah mall terbanyak di dunia. Rata-rata kebutuhan masyarakat Kota Jakarta menjadikan mall sebagai sumber hiburan. Berkunjung ke mall bagi masyakat Jakarta hampir menjadi kebutuhan penting. Dengan datang berkunjung ke mall yang sebagai tempat hiburan dan tempat melepas stres, mengapa tingkat stres dan depresi di Jakarta masih sangat tinggi. Hal ini menyatakan bahwa masyarakat Jakarta memerlukan sebuah ruang wisata baru yang dapat memiliki manfaat untuk mengurangi atau melepas stres.

\section{METODE}

Metode pembahasan dalam penulisan ini menggunakan metode pengumpulan data dan mengkaji yang berkaitan dengan wisata arsitektur di metropolis. Kedua menggunakan metode pengumpulan data yang berkaitan dengan tingkat stres masyarakat perkotaan. Kemudian mengaitkan literatur tentang wisata dengan proyek yang akan di desain. Lalu, Studi komparasi proyek yang sudah ada, melakukan analisi tapak yang mencakup makro dan mikro, analisis target market dan kebutuhannya, dan analisis program kegiatan.

\section{DISKUSI DAN HASIL}

Hasil penelitian/ desain harus menjelaskan setiap temuan penelitian/ hasil desain secara rinci pada bagian ini. Setiap informasi yang didapat dari suatu sumber yang sudah dipublikasi harus dikutip dengan menggunakan format APA (American Psychological Association). Gambar atau ilustrasi memungkinkan untuk ditampilkan dalam satu bidang yang lebih besar namun disarankan untuk tidak merubah format tampilan gambar dan di buat dengan layout in line with text.

\section{Definisi proyek}

Meditation Hub merupakan proyek berskala perkotaan. Proyek ini menjadi solusi dari tingginya tingkat stres yang dialami masyarakat Kota Jakarta akibat tingginya jam kerja, kemacetan, dan kurangnya interaksi sosial. Dalam proyek "Meditation Hub", masyarakat akan diajak sejenak mundur dari kehidupan perkotaan yang dituntut oleh waktu dan berbagai macam kesibukan untuk mencari kedamaian, ketenangan pikiran dan jiwa agar mencapai titik keseimbangan diri untuk dapat kembali beraktivitas dalam kondisi yang optimal.

Proyek ini merupakan salah satu wisata arsitektur yang menawarkan cara untuk melepaskan stres dengan cara "escape" melewati metode meditasi, memberikan pengalaman dalam merileksasi tubuh, mengkosongkan pikiran, dan membangkitkan semangat kita kembali. Terdapat beberapa program yang ditawarkan seperti Pra Meditation for mind management, Meditation for body \& soul management, dan After meditation for situation \& social management. 


\section{Program kegiatan}

Proyek Meditation Hub menggunakan metode meditasi sebagai cara untuk membantu masyarakat Kota Jakarta untuk mengurangi dampak stres yang di timbulkan akibat masalahmasalah yang dihadapi. Meditasi menurut Dhayana (Zen) merupakan aktivitas perenungan mendalam terhadap suatu tujuan. Aktivitas ini merupakan usaha antara yang membawa kesadaran menuju samadi, yaitu terserapnya kesadaran diri sebagai kesadaran terbatas kedalam kesadaran Tuhan yang meliputi kesadaran semesta yang tidak terbatas. Menurut Spektrum ajaran Buddha, meditasi merupakan usaha membangun ketenangan pikiran yang terkonsentrasi yang bisa melihat dengan jelas sifat sebenarnya dari semua hal yang bersifat fenomena, keadaan ideal dari batin yang sehat. Didalam proyek "Meditation Hub" terdapat 3 tahapan kegiatan yang akan di lakukan oleh pengunjung, yaitu

\section{Mind Management}

Pada tahap pertama merupakan kegiatan transisi sebelum pengunjung melakukan kegiatan utama yaitu meditasi. Pada tahap ini pengunjung akan diajak untuk menyiapkan diri untuk melakukan meditasi dimana pikiran pengunjung akan ditenangkan dan dikosongkan melalui ruang-ruang instalasi hingga sampai titik dimana pengunjung secara tidak sadar masuk ke dunia meditatif. Pencapaian ketenangan pikiran pengunjung melalui ruang arsitektur dengan pendekatan fenomenologi arsitektur. Tahap ini merupakan tahapan Pra-Meditation.

\section{Soul and Body Management}

Pada tahap kedua pengunjung akan melakukan kegiatan utama didalam program proyek ini, yaitu meditasi. Pengunjung akan melakukan teknik-teknik dasar meditasi melalui meditator berpengalaman. Kegiatan ini akan berlangsung selama kurang lebih 15-20 menit.

\section{Situation Management}

Pada tahap ketiga, merupakan tahapan terakhir dimana setelah pengunjung selesai melakukan meditasi, pengunjung bebas melakukan kegiatan yang bersifat relaksasi. Dalam tahapan ini terdapat beberapan kegiatan yang disediakan dan pengunjung bebas memilih. Kegiatan tersebut antara lain:

1. Kelas meditasi teh

Melalui teh menjadi alat bantu untuk meditasi, karena proses pembuatan teh sampai meminum teh merupakan salah satu proses yang dapat membantu membuat sesorang menjadi tenang.

2. Kelas membuat Lilin Aromaterapi

Aromaterapi sudah lama digunakan untuk relaksasi ketika dilanda kecemasan atau stress berlebih. Aromaterapi dipercaya dapat memberikan efek relaksasi serta mengendalikan sistem saraf simpatis, yaitu sistem saraf yang bertanggung jawab pada respon stres fight or flight (melawan atau melarikan diri) dan gejala fisiknya, seperti tangan berkeringat atau jantung yang berdegup kencang.

\section{Ruang Pondering}

Pondering ialah kegiatan merenung atau memikirkan sesuatu secara hati-hati, terutama sebelum membuat keputusan untuk mencapai hasil yang baik. Jadi di ruang ini pengunjung akan lebih memiliki kebebasan untuk melakukan kegiatannya sendiri.

\section{Ruang Perpustakaan}

Pengujung disediakan tempat untuk menghabiskan waktunya dengan bersantai dengan membaca buku atau yang lainnya.

5. Cafe Organik

Di Cafe pengunjung dapat menikmati berbagai macam makanan dan minuman yang bersifat organik. Baik untuk kesehatan tubuh dan pikiran, pengunjung akan dikenalkan dengan 
makanan minuman yang dapat baik untuk tubuh.

\section{Analisis Kawasan}

Jakarta Selatan menjadi pemilihan lokasi untuk pengamatan. Dengan luas wilayah sebesar 141,27 km2 dan total penduduk 2.164.070 jiwa ( BPS,2014), Jakarta Selatan terdiri dari 10 Kecamatan. Jakarta Selatan merupakan kota administrasi paling kaya dibandingkan dengan wilayah lainnya. Hal itu dikarenakan banyaknya perumahan warga dengan kelas menengah ke atas terdapat di kawasan Jakarta Selatan. Pusat Pemerintahannya terdapat di Kebayoran Baru. Jakarta Selatan merupakan kawasan dengan suhu udara paling dingin se-Jakarta, dikarenakan bagian selatan Jakarta merupakan pegunungan dengan curah hujan tinggi. Selain itu, kawasan Kebayoran Lama dan Kebayoran Baru masih memiliki suasa asri dengan udara cukup bersih. Karena di kawasan tersebut masih terdapat banyak penghijauan.

Analisis lingkungan tapak

Sebagian besar daerah Kebayoran baru merupakan daerah pemukiman. Kawasan ini merupakan Pusat Pemerintahan dari Jakarta Selatan, selain itu terdapat pusat bisnis (Sudirman Business DIstric) dan terdapat satu Terminal Bus dalam kota (terminal BLOK-M). Kebayoran Baru merupakan satu-satunya daerah yang dirancang oleh Arsitek pada jaman dahulu. Daerah ini mempunyai konsep 'Kota Taman', dimana ruang terbuka hijau menjadi prioritas utama di kawasan tersebut. Hingga sampai sekarang kawasan Hijau di Kebayoran Baru masih menjadi perhatian utama agar kawasan tersebut tetap asri, sejuk dan tetap menjadi kota taman.

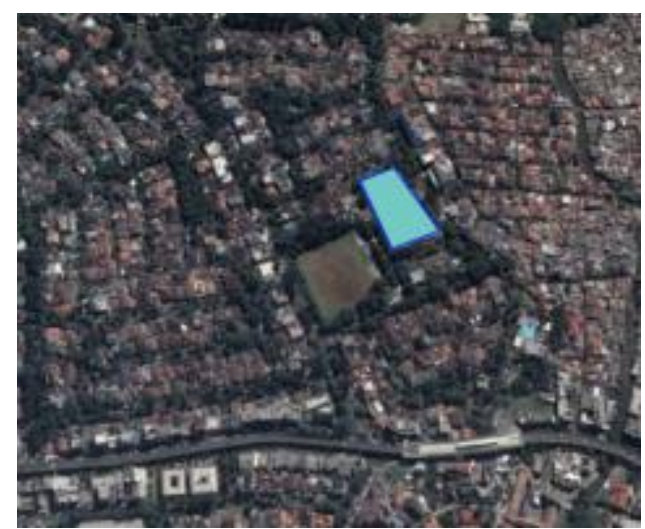

Gambar 1. Lokasi Tapak Terpilih

Tapak terpilih berukuran $5.320 \mathrm{~m}^{2}$ berada di jalan Birah Kebayoran Baru Jakarta Selatan dengan ketentuan tapak yaitu KDB 40\%, KLB 1.6, KTB 55\%, KB 4, KDH 30\%, Tipe Tunggal.

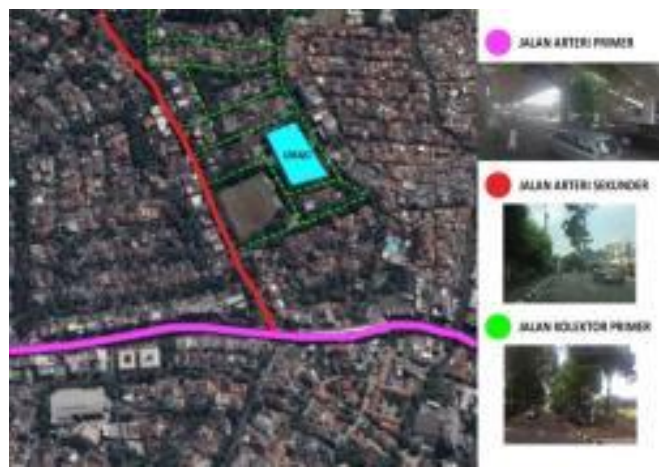

Gambar 2. Analisi Tapak Hierarki Jalan 


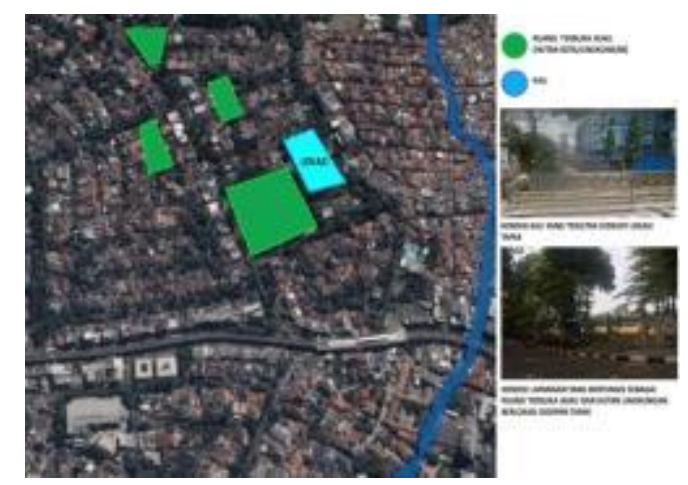

Gambar 3. Analisi Tapak Ruang Terbuka

\section{Proses gubahan massa}

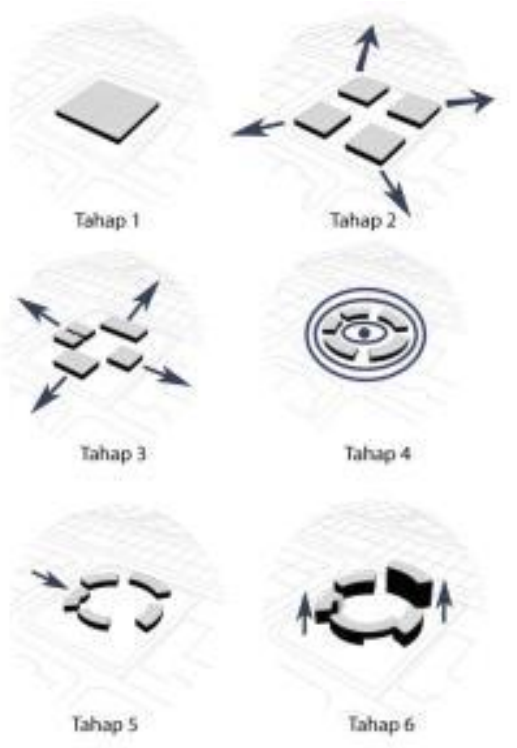

Gambar 4. Proses Pembentukan Gubahan Massa Bangunan

Proses pembentukan gubahan massa dimulai dari menempatkan sebuah blok masif yang menyesuaikan dengan bentuk tapak. Proses selanjutnya massa dipotong dan dipisahkan agar terdapat ruang terbuka ditengahnya. Pemisahan massa berdasarkan pengelompokan program kegiatan. Pada tahap ke 3, massa disesuaikan bentuknya dengan besaran masing-masing program. Pada tahap selanjutnya, massa di letakkan sesuai dengan arah dari alur kegiatan untuk pengunjung. Kemudian massa di lengkungkan untuk menghilangkan area sudut. Dengan mengambil dari filosofi bentuk lingkarang sebagai cerminan dari manfaat dan tujuan proyek.

Kemudian posisi masa di maju mundurkan agar tidak terlihat monoton dengan posisi yang sama. Tanpa menghilangkan konsep filosofi bentuk dari lingkaran, dengan menyambungkan garis bangunan dan garis lansekap massa akan tetap terlihat sebagai lingkaran untuh dari atas. Proses terakhir yaitu dengan mengatur tinggi masing-masing massa bangunan. Massa dengan program utama memiliki jumlah lantai yang paling tinggi yaitu empat lantai. Hal ini dikarenakan massa tersebut diciptakan untuk menjadi titik pusat penglihatan untuk pengunjung. 


\section{Analisa Konsep Perancangan}

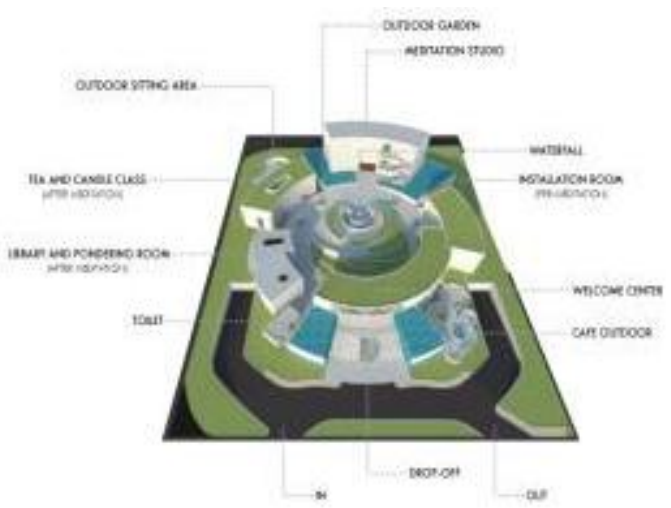

Gambar 5. Massa Bangunan

Bangunan memiliki beberapa program utama yaitu pra-meditation (sebelum meditasi), meditation (meditasi), dan after-meditation (sesudah meditasi). Pra-meditation terdiri dari ruang-ruang instalasi yang memakai pendekatan fenomenologi arsitektur sebagai metode desainnya. Metode tersebut diterapkan untuk tujuan memunculkan perspeksi seseorang terhadap suatu ruang hingga kesadaran seseorang untuk mencapai tahap kestabilan pikiran sebelum melakukan kegiatan meditasi. Pada tahap ini terdiri dari 10 ruang instalasi. Ruanganruangan itu terdiri dari:

\section{Dark Room}

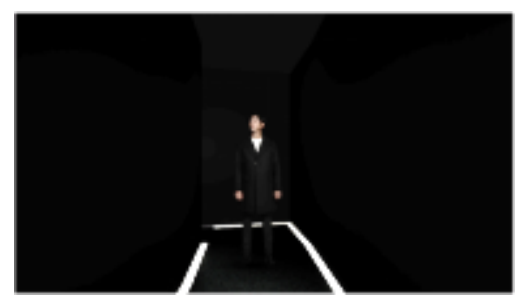

Gambar 6. Ilustrasi Ruang

Pada ruang pertama pengunjung akan memasuki dark room dimana didalam ruang ini penuh dengan kegelapan tanpa ada suara. Petunjuk jalan satu-satunya adalah lampu led yang terletak dilantai yang akan mambawa pengunjung untuk keruangan selanjutnya. Pada ruangan ini dengan menggunakan kegelapan untuk membangunkan sense manusia yang berada di titik rendah.

\section{Dark Alley}

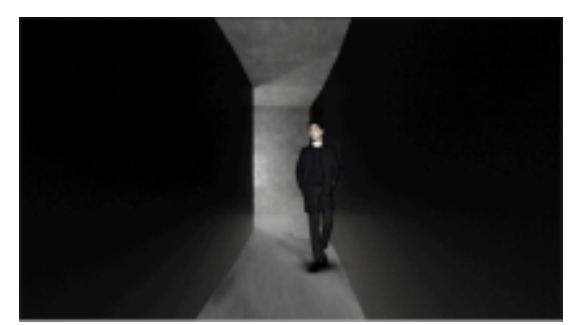

Gambar 7. Ilustrasi Ruang 
Dark Alley merupakan ruangan selanjutnya. Masih dengan menggunakan kegelapan sebagai fokus utamanya, pada ruang ini cahaya diujung ruang digunakan sebagai tanda untuk menuju ke ruang selanjutnya.

\section{Visualitation Room}

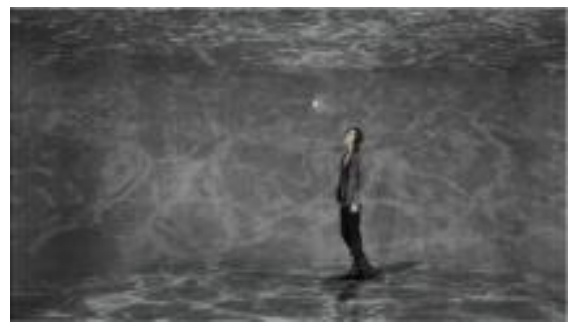

Gambar 8. Ilustrasi Ruang

Visualitation digunakan untuk membangunkan sense pendengaran. Diruangan ini pengunjung seolah-olah berada ditengah-tengah air. Efek bayangan dan efek suara dari air digunakan untuk membawa pikiran dan tubuh pengujung ke tahap ketenangan.

Light Room

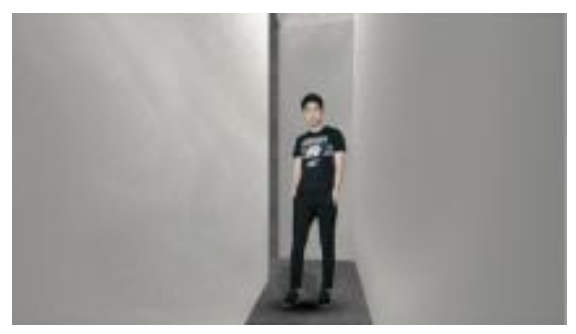

Gambar 9. Ilustrasi Ruang

Terang yang digunakan dalam ruangan ini bukanlah berasal dari cahaya lampu maupun cahaya matahari, tetapi dengan penggunaan material dinding, atap, dan lantai dengan warna terang yang membuat ruangan tersebut menjadi terang.

Light and Shadow Room

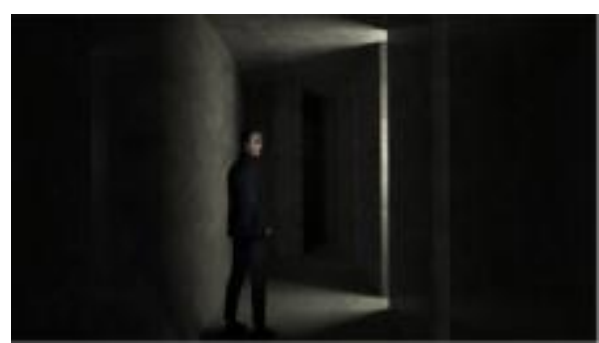

Gambar 10. Ilustrasi Ruang

Dengan hasil bayangan dan cahaya yang dihasilkan dari kisi-kisi diantara dinding-dinding akan membuat setiap pengujung memiliki pemandangan yang berbeda di setiap jam nya. 


\section{Mirror Stair}

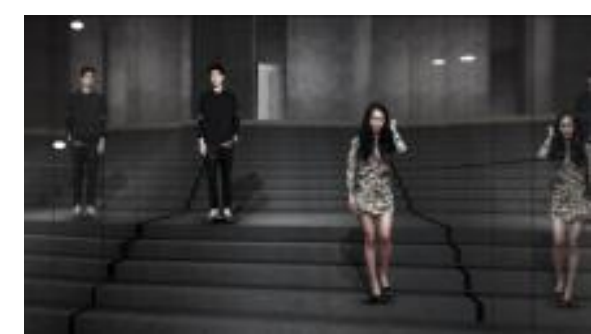

Gambar 11. Ilustrasi Ruang

Tangga yang di kelilingi oleh cermin akan menghasilkan efek bayangan yang tidak ada habisnya. Pengujung akan merasakan sensasi nya saat melihat bayangan akan dirinya sendiri jika berdiri dari atas tangga lalu jalan sampai ke bawah.

\section{Path of Light}

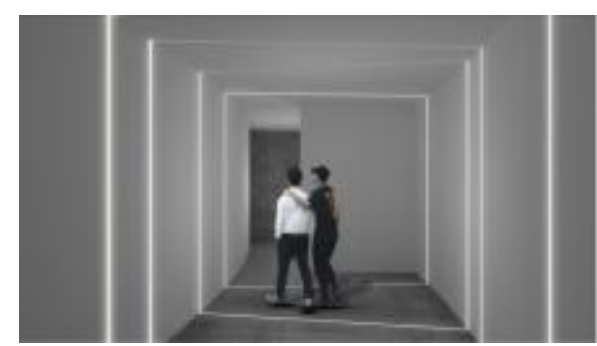

Gambar 12. Ilustrasi Ruang

Garis-garis cahaya tipis yang dihasilkan oleh led akan menjadi petunjuk bagi pengunjung menuju lorong berikutnya hingga menuju ke ruangan selanjutnya.

\section{Silent Room}

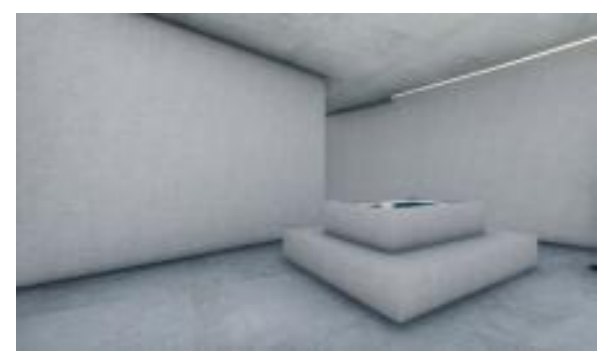

Gambar 13. Ilustrasi Ruang

Pada ruangan selanjutnya, pengujung dapat duduk-duduk santai untuk menikmati kesunyian yang ada didalam ruang ini.

\section{Water Stair}

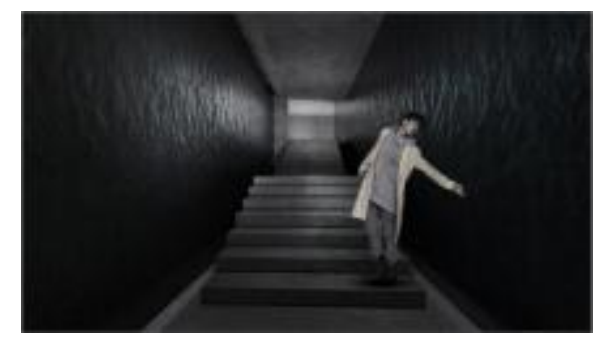

Gambar 14. Ilustrasi Ruang 
Tangga sebagai akses menuju ke ruang selanjutnya, dinding air yang menjadi simbol dingin dan akan memberikan efek seolah-olah pengunjung yang melewatinya akan terbawa tenggelam kedalam air.

\section{Water Fall}

Waterfall merupakan ruang instalasi terakhir dimana pengujung dapat duduk dengan menikmati air mancur yang berasal dari void kecil di lantai atas. Terdapat ramp yang akan membawa pengunjung menuju ke area luar bangunan sehingga pengunjung dapat melanjutkan untuk kegiatan selanjutnya.

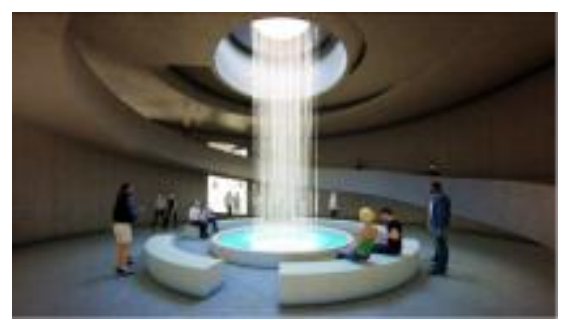

Gambar 15. Ilustrasi Ruang

Zona meditasi merupakan dimana pengunjung akan melakukan kegiatan meditasi. Terdapat tiga level studio dimana kapasitas untuk satu studio bisa untuk 10-15 orang. Kegiatan akan dimulai dengan pengenalan teknik-teknik yang akan digunakan dalam meditasi selama 15-20 menit. Ruangan sengaja dirancang dengan kesederhanaan, kepolosan, dan keaslian material. Menurut Tadao Ando, suatu ketiadaan ornamen diciptakan dalam ruang sebagai upaya menyadarkan manusia akan apa yang di dapat dari suatu ketidaan ornament tersebut. Dengan mengusung konsep ruangan "can see but cannot be seen", disini pengunjung dapat mendapatkan privacy selama meditasi.

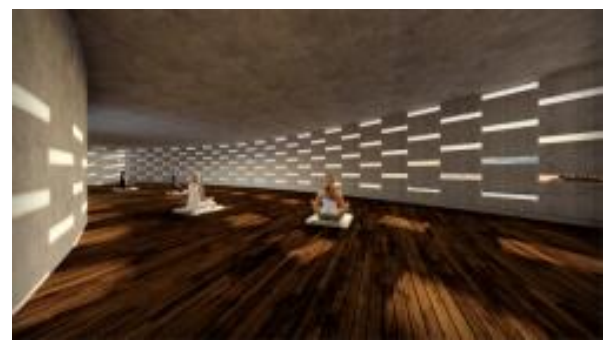

Gambar 16. Ilustrasi Ruang

Pada zona After Meditation adalah kegiatan relaksasi kembali setelah melakukan kegiatan meditasi, disini pengunjung akan lebih mengenal diri mereka sendiri dan bagaimana cara berdamai dengan stres. Disini pengunjung dapat memilih beberapa program yang ditawarkan diantaranya, kelas meditasi dengan bantuan teh, karena proses membuat teh sampai meninum teh merupakan salah satu proses yang dapat membantu meditasi. Selain kelas meditasi dengan bantuan teh terdapat juga kelas lain seperti kelas meditasi dengan lilin aromaterapi, aromaterapi sudah lama digunakan untuk relaksasi ketika dilanda kecemasan atau stress berlebih. Aromaterapi dipercaya dapat memberikan efek relaksasi serta mengendalikan sistem saraf simpatis, yaitu sistem saraf yang bertanggung jawab pada respon stres fight or flight (melawan atau melarikan diri) dan gejala fisiknya, seperti tangan berkeringat atau jantung yang berdegup kencang. Selanjutnya terdapat ruang untuk relaksasi yaitu ruang pondering, pondering ialah kegiatan merenung atau memikirkan sesuatu secara hati-hati, terutama sebelum membuat keputusan untuk mencapai hasil yang baik. Ruangan terbuka yang asri sangat mendukung kegiatan ini, furniture yang mendukung pengunjung dapat berinteraksi satu sama lain. Warna yang datang dari alam seperti warna hijau dari 
tumbuhan dan warna biru dari langit.

\section{Zoning Bangunan}

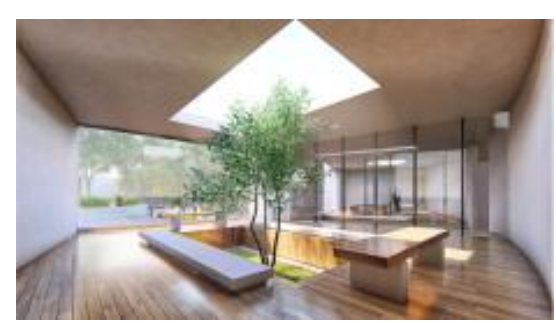

Gambar 17. Ilustrasi Ruang

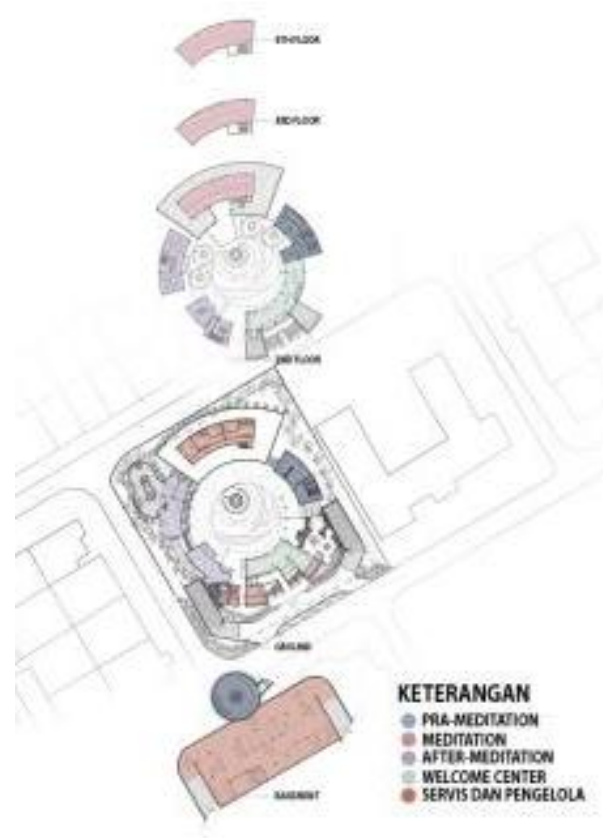

Gambar 18. Zoning Bangunan

Pembagian zoning pada bangunan dibagi berdasarkan kelompok program. Pengelompokan program dibagi per bangunan. Terdapat 5 massa bangunan terpisah berdasarkan zoning program. Pada bangunan zoning welcome center terdapat infromation, lounge, cafe, souvenir shop. Pada zona pra-meditation terdapat ruang-ruang instalasi. Pada zona meditation terdapat studio meditasi. Pada zona after-meditation terdapat kelas teh, kelas lilin aromaterapi, perpustakaan, ruang pondering, dan cafe organik. Pada zona servis terdapat parkir mobil, parkir motor, ruang trafo dan genset, ruang pompa, toilet pengunjung, dan kantor pengelola.

\section{KESIMPULAN DAN SARAN}

Mediation Hub adalah salah satu wisata arsitektur yang menawarkan cara untuk melepaskan stres dengan cara "escape" melewati metode meditasi, memberikan pengalaman dalam merileksasi tubuh, mengkosongkan pikiran, dan membangkitkan semangat kita kembali. Terdapat beberapa program yang ditawarkan seperti Pra Meditation for mind management, Meditation for body \& soul management, dan After meditation for situation \& social management.

Meditation Hub mampu menjadi destinasi dan atraksi wisata ditengah kepadatan dan dinamika ruang metropolis. Sebagai ruang "escape" dari kepadatan kota, pengunjung dapat menggunakan Meditation Hub sebagai sarana transit, sarana beristirahat dari kepadatan kota 
sejenak lalu kembali beraktivitas seperti sedia kala. Kompleksitas karakter yang di derita pengunjung seperti lelah karena bekerja, kecemasan yang berkepenjangan sehingga berakibat stres menghasilkan beberapa program yang ditawarkan untuk meditasi yang sesuai dengan kebutuhan masyarakat metropolis.

Program yang ditawarkan bersifat relaksasi, di tahap Pra Meditation for mind management pengunjung di anjurkan untuk melakukan latihan pernafasan sambil berjalan untuk pengalaman ruang dengan pendekatan fenomenologi arsitektur. Dengan mengendalikan pernapasan, pengujung jadi memusatkan pikiran pada pernapasan yang lambat dan dalam sehingga membantu unyuk melepaskan diri dari pikiran dan sensasi yang memicu stres. Meditation for body \& soul management adalah salah satu cara relaksasi yang dapat membuat seseorang merasa lebih rileks dan segar, dengan cara mengatur nafas dan menghitung interval pernafasan kapan harus menghembuskan kapan harus menarik nafas. After Meditation for situation \& social management adalah kegiatan relaksasi kembali setelah melakukan kegiatan meditasi, disini pengunjung sudah dapat mengenal diri mereka sendiri dan bagaimana cara berdamai dengan stres.

Rasa yang diberikan kepada kota adalah rasa keseimbangan antara bekerja dan beristirahat. Penduduk dapat beristirahat sejenak tanpa perlu meninggalkann pekerjaan atau keluar dari kota. Rasa Keseimbangan pada penduduk kota sangat dibutuhkan guna membangun kota yang baik kedepannya. Bekerja akan lebih produktif jika waktu istirahat yang diberikan cukup. Bukan hanya kesehatan jasmani yang diperlukan tetapi juga kesehatan rohani, keduanya dapat didapatkan lewat meditasi. Kesehatan jasmani didapatkan ketika badan kita diam dan beristirahat, sedangkan pikiran didapatkan ketika kita mengkosongkan pikiran dengan merenung. Memikirkan sesuatu dengan hati-hati sebelum memutuskan sesuatu. Karakter signifikan pengunjung yang datang adalah yang memiliki masalah dengan kesehatan jasmani maupun rohani. Penduduk yang ingin beristirahat dari penatnya situasi perkotaan, kabur sejenak dari kesemerawutan pekerjaan, dan ingin mencari suasana baru. Pengunjung membutuhkan cara untuk melepaskan stres melewati metode meditasi yang ditawarkan dengan banyak program sesuai kebutuhan pengunjung. Beberapa tahap disediakan mulai dari tahap pemula hingga tahap advance.

Merancang sebuah program wisata di area Metropolis, berhadapan dengan kompleksitas penduduk Jakarta guna menghasilkan program yang sesuai dengan kebutuhan masyarakat metropolis. Karakter simplisitas yang ditampilkan pada bangunan, dapat menjadi atraksi wisata yang menarik bagi masyarakat dan program yang bersifat meditasi untuk memberikan rasa "keseimbangan" bagi masayarakat kota Jakarta.

\section{UCAPAN TERIMA KASIH}

Penulis menyampaikan terima kasih kepada Bapak/ Ibu/ Sdr, atas kesediaannya untuk menelaah jurnal yang dimuat pada edisi ini.

\section{REFERENSI}

Specth, Jan. (2014). Architectural Tourism Building for Urban Travel Destinations. Munich :

Springer Gabler.

Holl,Steven. Pallasma, Juhani. Question Of Perception: Phenomenology of Architecture

Rasmussen, Steen Eiler. (1959). Experiencing Architecture

Law, Alissa. (2018). Stress Management

Rai, AK. (2009). Stress Management

Brooks, Jennifer. (2012). Zen Meditation

Hasil Riskesdas Tahun 2007

Hasil Riskesdas Tahun 2013

https://id.wikipedia.org/wiki/Metropolitan

https://www.atlasandboots.com/most-stressed-countries/ 
https://www.usnews.com/news/best-countries/articles/2016-09-14/the-10-most-depressedcountries

http://momdadi.com/momdadi/gangguan-depresi-urutan-keempat-penyakit-di-dunia/ http://jabar.tribunnews.com/2017/04/08/2020-penyakit-akibat-depresi-menjadi-peringkatnomor-dua-dunia

https://www.kompasiana.com/atep_afia/5508e6a2a333112a452e39af/17-4-juta-orang-alamistres-dan-depresi

http://sehatnegeriku.kemkes.go.id/baca/rilis-media/20121009/596648/waspada-terhadapdepresi-terselubung-dan-penyakit-penyertanya/

http://poskotanews.com/2013/05/20/pengidap-gangguan-jiwa-terbanyak-di-dki-jakarta/ http://politik.news.viva.co.id/news/read/859722-depresi-gangguan-kesehatan-ketigaterbanyak-di-jakarta http://ryeinspirasi.blogspot.com/2011/12/tahapan-stres-drrobert-jvan-amberg-1979.html http://marketplus.co.id/2014/09/jakarta-kota-dengan-banyak-mall-di-dunia/ https://m.merdeka.com/sehat/tenang-dan-rileks-dengan-meditasi-teh.html https://id.wikipedia.org/wiki/Daerah_Khusus_Ibukota_Jakarta\# https://id.wikipedia.org/wiki/Kota_Administrasi_Jakarta_Selatan https://id.wikipedia.org/wiki/Kebayoran_Baru,_Jakarta_Selatan https://kbbi.kemdikbud.go.id/ 